\title{
Metals, models, and isotopes: Insights into the biogeochemical cycling of trace nutrients in the ocean
}

\author{
SETH G. JOHN ${ }^{1}$, Tim M. CONWAY ${ }^{2}$, THOMAS WEBER ${ }^{3}$, \\ TIM DEVRIES ${ }^{4}$, AlESSANDRO TAGLIABUE $^{5}$, HENGDI \\ LIANG $^{6}$, BENOIT PASQUIER $^{7}$
}

${ }^{1}$ University of Southern California, sethjohn@usc.edu

${ }^{2}$ University of South Florida, tmconway@usf.edu

${ }^{3}$ University of Rochester, t.weber@rochester.edu

${ }^{4}$ University of California SB, tdevries@geog.ucsb.edu

${ }^{5}$ University of Liverpool, a.tagliabue@liverpool.ac.uk

${ }^{6}$ University of Southern California, hengdili@usc.edu

${ }^{7}$ University of Southern California, bp_358@usc.edu

The past few years has seen revolutions in apparently dissimilar fields, one in the availability of ocean trace-metal concentration and isotope data available through the GEOTRACES program, and another in techniques to model steady-state global tracer distributions using OCIM techiques. Yet, at the intersection between the two, recent efforts have leveraged new data and new modeling techniques in order to better understand the global biogeochemical cycling of tracemetal nutrients in the oceans.

OCIM type models are particularly well suited to exploring trace-metal biogeochemical cycling. New tools such as the AWESOME OCIM allow such models to be run on a laptop, using code specifically written for non-expert modelers. Steady-state tracer distributions can be solved in just a few seconds, allowing for thousands of model runs as models are 'tuned' to match observations. In this way, various hypotheses about metal isotope cycling can be tested. Hypotheses can be rejected if there is no version of the model consistent with observations, while plausible models can be used to probe the specific conditions (parameter values) under which biogeochemical processes might occur.

OCIM models of several trace-metal nutrients hilight the power of this approach. Fe concentrations and $\delta^{56} \mathrm{Fe}$ can be used in OCIM models to fingerprint Fe sources, and quantify biological cycling. $\mathrm{Zn}$ and $\delta^{66} \mathrm{Zn}$ models constrain both the rates of biological $\mathrm{Zn}$ uptake and the pathways by which $\mathrm{Zn}$ is transferred into the deep ocean. $\mathrm{Cd}$ and $\delta^{114} \mathrm{Cd}$ models can be used to elucidate the mechanisms behind the global similarity between $\mathrm{Cd}$ and $\mathrm{P}$ distributions. $\mathrm{Ni}$ and $\delta^{60} \mathrm{Ni}$ hilight the particular biological controls which allow excess Ni to persist globally in oligotrophic gyres, and hint at the possibility of past-ocean Ni limitation. And $\mathrm{Cu}$ models, along with the lack of $\delta^{65} \mathrm{Cu}$ variability, can be used to hilight previously unconsidered sources of $\mathrm{Cu}$ to the oceans. 